\title{
Characterization of the Extended Carbohydrate Binding Site of Concanavalin A: Specificity for Interaction with the Nonreducing Termini of $\alpha-(1 \rightarrow 2)$-Linked Disaccharides ${ }^{1}$
}

\author{
TAFFY J. WILLIAMS, *,2 LOUIS D. HOMER,* JULES A. SHAFER, $\dagger$ \\ IRWIN J. GOLDSTEIN, $\uparrow$ PER J. GAREGG, $\ddagger$ HANS HULTBERG, \\ TOMMY IVERSEN, $\ddagger$ AND ROLF JOHANSSON $\ddagger$
}

\footnotetext{
${ }^{*}$ Naval Medical Research Institute, Bethesda, Maryland 20014; + Department of Biological Chemistry, University of Michigan, Ann Arbor, Michigan 48109; and $¥$ Department of Organic Chemistry, Arrhenius Laboratory, University of Stockholm, S-106 91 Stockholm, Sweden
}

Received July 18, 1980

\begin{abstract}
$p$-Nitrophenyl 2-O- $\alpha$-D-galactopyranosyl- $\alpha$-D-mannopyranoside and $p$-nitrophenyl 2-O$\alpha$-D-glucopyranosyl- $\alpha$-D-mannopyranoside were synthesized and the interactions of these disaccharides with concanavalin A (con A) were characterized. The kinetics of binding of the galactopyranosyl-containing disaccharide to con A were found to be similar to those observed with monosaccharides in that monophasic time dependencies for binding were observed. The glucopyranosyl-containing disaccharide, however, exhibited biphasic time dependencies which were similar to those previously observed for the binding of $p$ nitrophenyl 2-O- $\alpha$-D-mannopyranosyl- $\alpha$-D-mannopyranoside to con $\mathrm{A}$. These results support a model wherein the $\alpha-(1 \rightarrow 2)$-linked disaccharides which exhibit biphasic binding kinetics must be able to bind to con $A$ in two different and mutually exclusive orientations. The ability to bind to con $A$ in two orientations is shared by $\alpha-(1 \rightarrow 2)$-linked disaccharides in which both glycosyl residues can interact separately with the primary glycosyl binding site of con A. According to the model, the initial fast phase of the biphasic reaction reflects binding of the ligand in two orientations so that two complexes are formed in amounts determined by the relative values of the rate constants for formation of each complex. The subsequent slow phase is proposed to reflect a slow equilibration of the less stable complex to the thermodynamically more stable one. In the more stable complex, the glycosyl residue at the reducing end of the disaccharide occupies the primary glycosyl binding site. The added stability of this complex is attributed to extended interactions between con $A$ and groups on the second glycosyl residue. An axial orientation of $\mathrm{OH}-2$ of the second glycopyranosyl residue appears to be the most important determinant for the extended interaction.
\end{abstract}

It has recently been reported $(1,2)$ that concanavalin $\mathrm{A}$ (con $\mathrm{A}$ ) binds the $p$-nitrophenyl and the 4-methylumbelliferyl glycosides of 2-O- $\alpha$-D-mannopyranosyl- $\alpha-\mathrm{D}-$ mannopyranoside via a biphasic time-dependent process. This contrasts sharply with the monophasic process observed for the binding of monosaccharides to con $\mathrm{A}$.

\footnotetext{
1 This study was supported in part by the Naval Medical Research Development Command, Research Task Nos. MR0410101.0146 and MF58524013.1044. Further support was supplied by United States Public Health Service Grants AM-10171, AM-09276, T32CA-09015-02, the Swedish Natural Science Research
}

The simplest scheme that can account for the biphasic association reaction is one in which the $\alpha-(1 \rightarrow 2)$-linked disaccharides are proposed (1) to bind to con $\mathrm{A}$ in two different and mutually exclusive orientations as shown in Figs. 1A and B. According to the proposed reaction scheme

Council, and Stiftelsen Bengt Lundquists Minne. The opinions or assertions contained herein are personal and are not to be construed as official or reflecting the view of the Navy Department or the naval service at large.

${ }^{2}$ To whom reprint requests should be sent. 


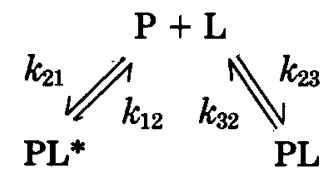

the initial rapid phase reflects formation of two complexes in amounts determined by the relative values of the rate constants for formation of each complex. The subsequent slow phase is postulated to reflect equilibration of the two complexes according to their relative thermodynamic stabilities. The greater stability of one binding mode over the other is proposed to arise from the ability of con $A$ to interact simultaneously with groups on both glycosidic residues of the disaccharide (1).

Biphasic, time-dependent interactions resulting in complex formation between protein and ligand are generally ascribed to the reaction scheme of Eq. [2] rather than that of Eq. [1]

$$
\mathrm{P}+\mathrm{L} \rightleftharpoons \mathrm{PL} \rightleftharpoons \mathrm{PL} *
$$

The two reaction schemes are conceptually different in that the slow phase of reaction [2] is attributed to some type of change in the conformation of the protein-ligand complex, whereas the slow phase of reaction [1] is attributed to equilibration of the two binding modes via a pathway which involves dissociation of the bound ligand. For this con A system, Eqs. [1] and [2] are mathematically indistinguishable and it is not possible to select either reaction schemes of Eqs. [1] or [2] solely on the basis of the time-dependent changes in the spectral properties which accompany ligand binding. In this work, studies are reported of the interaction of con A with $\alpha$-D-Glc $p$ - $(1 \rightarrow 2)-\alpha$-D-Man $p-(1 \rightarrow O)$ -

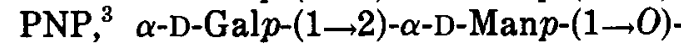

\footnotetext{
${ }^{3}$ Abbreviations used: $\alpha-\mathrm{D}-\mathrm{Gal} p-(1 \rightarrow 2)-\alpha-\mathrm{D}-\mathrm{Man} p-$ $(1 \rightarrow O)$-PNP, $p$-nitrophenyl 2-O- $\alpha$-D-galactopyranosyl$\alpha$-D-mannopyranoside; $\alpha$-D-Gle $p$ - $(1 \rightarrow 4)-\alpha$-D-Glc $p$ $(1 \rightarrow O)$-PNP, $p$-nitrophenyl 4-O- $\alpha$-D-glucopyranosyl$\alpha$-D-glucopyranoside; $\alpha$-D-Glc $p-(1 \rightarrow 2)-\alpha$-D-Man $p$ $(1 \rightarrow O)$-PNP, $p$-nitrophenyl $2-0$ - $\alpha$-D-glucopyranosyl$\alpha$-D-mannopyranoside; $\alpha$-D-Glc $p$ - $(1 \rightarrow O)$-PNP, $p$-nitrophenyl $\alpha-\mathrm{D}$-glucopyranoside; $\alpha$-D-Man $p-(1 \rightarrow O)$ PNP, $p$-nitrophenyl $\alpha$-D-mannopyranoside; $2-O$-Me$\alpha$-D-Man $p$-(1孔O)-PNP, p-nitrophenyl 2-O-methyl$\alpha$-D-mannopyranoside; $\alpha$-D-Man $p-(1 \longrightarrow 2)-\alpha-\mathrm{D}-\mathrm{Man} p$ -
}

PNP, and $\alpha$-D-Gle $p-(1 \rightarrow 4)-\alpha-\mathrm{D}-\mathrm{Glc} p-(1 \rightarrow$ $O)$-PNP which provide strong evidence for the existence of two binding modes for disaccharides as depicted in Eq. [1] and in Figs. 1A and B. Furthermore, some of the specificity requirements for the interaction of con A with the glycosyl group at the nonreducing glycosyl group of $\alpha-(1 \rightarrow 2)$ linked disaccharides are also characterized in this work.

\section{MATERIALS AND METHODS}

Kinetic and thermodynamic measurements. Kinetic and equilibrium studies were performed using con A consisting of $100 \%$ intact subunits (3) in a 0.5 $M$ acetate buffer at $\mathrm{pH} 5.0$, containing $0.1 \mathrm{mM} \mathrm{MnCl}_{2}$ and $0.1 \mathrm{mM} \mathrm{CaCl}$ and adjusted to $\Gamma / 20.5$ with $\mathrm{NaCl}$. The concentration of the ligands was determined using a measured molar absorptivity of $10,000 \mathrm{~cm}^{-1}$ $\mathrm{M}^{-1}$ at $305 \mathrm{~nm}$ for the nitrophenyl glycosides (3). An absorptivity of $28,770 \mathrm{~cm}^{-1} \mathrm{M}^{-1}$ at $280 \mathrm{~nm}$ was used to calculate concentrations of con A protomers (4). All concentrations of con A refer to concentration of protomeric units.

Equilibrium measurements were made on an Aminco DW-2 spectrophotometer thermostated at $25^{\circ} \mathrm{C}$. Equilibrium constants were determined by nonlinear least-squares fits of

$$
\left[\mathrm{L}_{\mathrm{b}}\right]=\frac{K_{a}\left[\mathrm{~L}_{\mathrm{f}}\right]}{1+K_{\mathrm{a}}\left[\mathrm{L}_{\mathrm{f}}\right]} n\left[\mathrm{P}_{\mathrm{t}}\right] \text {, }
$$

where $\left[L_{f}\right]$ and $\left[L_{b}\right]$ are the free and bound ligand concentrations, $\left[P_{t}\right]$ is the total concentration of protein, $n$ is the number of binding sites, and $K_{a}$ the equilibrium constant for association of ligand and con $A$.

Reaction rates and activation parameters were determined using an Aminco-Morrow stopped-flow apparatus interfaced with a Digital PDP-11/34 computer. All of the monophasic reactions and some of the biphasic association reactions were run under pseudo-first-order conditions $\left(\left[P_{t}\right] \geq 10\left[L_{t}\right]\right)$, and rate

$(1 \rightarrow O)-P N P, \quad p$-nitrophenyl 2-O- $\alpha$-D-mannopyranosyl- $\alpha$-D-mannopyranoside; $\alpha$-D-Man $p$ - $(1-O)$-MeUmb, 4-methylumbelliferyl $\alpha$-D-mannopyranoside; $\alpha$-DMan $p-(1 \rightarrow 2)-\alpha-D-M a n p-(1 \rightarrow 0)-M e I J m b, \quad$ 4-methylumbelliferyl 2-O- $\alpha$-D-mannopyranosyl- $\alpha$-D-mannopyranoside; $\alpha$-D-Man $p-(1 \longrightarrow 2)-\alpha-D-M a n p-(1 \rightarrow 2)-\alpha-D-$ Manp-(1_O)-MeUmb, 4-methylumbelliferyl 2-O- $\alpha$ D-mannopyranosyl-2- $O-\alpha$-D-mannopyranosyl- $\alpha-\mathrm{D}-$ mannopyranoside; $\alpha$-D-Man $p-(1 \longrightarrow O)$-Me, methyl $\alpha$-Dmannopyranoside; gle, gas-liquid chromatography; ms, mass spectrometry. 
constants were evaluated as described previously (1). Dissociation reactions were run by displacing chromogenic ligand from con A using $0.1 \mathrm{M} \alpha$-D-Manp$(1 \rightarrow O)$-Me. In these experiments, the con $\mathrm{A}$ and ligand both were present at equal concentrations of 50-100 $\mu \mathrm{M}$. The biphasic association reactions were also run under conditions wherein $\left[P_{t}\right] \geq 2\left[L_{t}\right]$. Rate constants were obtained from the best fit of the data to Runge-Kutta numerical integrations (using a computer) of the general differential rate equations which did not assume pseudo-first-order conditions $\left(\left[\mathrm{P}_{t}\right] \gg\left[\mathrm{L}_{\mathrm{t}}\right]\right)$. The fit of the observed biphasic association reactions to the scheme in Eq. [1] was constrained by the requirements that $K_{a}=K_{\mathrm{PL}}+K_{\mathrm{PL} \text {, }}$ and $k_{\text {off }}=k_{32}$, where $K_{a}$ is the value of the apparent equilibrium constant for association determined from an independent spectrophotometric titration and $k_{\text {off }}$ is the value of the rate constant observed for the first-order displacement of chromogenic ligand by 0.1 M $\alpha$-D-Man $p-(1 \rightarrow O)$-Me. The rate constants reported here are the average values obtained from at least three association reactions run at different concentrations of con A (125-150 $\mu \mathrm{M})$ and ligand (25-85 $\mu \mathrm{M})$. The standard deviations of the rate constants as determined in different kinetic runs was less than $10 \%$. Also there was no significant difference in the rate constants for the biphasic reactions as determined by the method in Ref. (1) and those determined by Runge-Kutta integration. The rate constants for the biphasic reactions reported in this work are those obtained from Runge-Kutta integration of the differential rate equations. The computer program using the Runge-Kutta integration of the differential equations varied rate constants and molar absorptivities until the least-square deviation was obtained between the observed time dependence of absorbance and that calculated from the integrated differential rate equations.

Synthesis of p-nitrophenyl 2-O- $\alpha$-D-galactopyrano-


glucopyranosyl- $\alpha-D$-mannopyranoside. Melting points are corrected and solutions were concentrated at reduced pressure below $40^{\circ} \mathrm{C}$. Optical rotations were measured at $20-22^{\circ} \mathrm{C}$ with a Perkin-Elmer 241 instrument. Separations were performed using silica gel (Merck) and Bio-Gel P2 columns. Gas-liquid chromatography/mass spectrometry was performed using a Varian MAT 311 instrument. ${ }^{13} \mathrm{C}$ and ${ }^{1} \mathrm{H}$ NMR spectra were recorded for all new compounds on a JEOL FX100 spectrometer, and were in agreement with the postulated structures.

$p$-Nitrophenyl 3-O-benzoyl-4,6-O-benzylidene- $\alpha-D$ mannopyranoside (1). A solution of $p$-nitrophenyl 4,6-O-benzylidene- $\alpha$-D-mannopyranoside (5) $(7.0 \mathrm{~g}, 18$ mmol) in pyridine $(210 \mathrm{ml})$ was cooled to $-45^{\circ} \mathrm{C}$. Benzoyl chloride $(2.1 \mathrm{ml}, 18.1 \mathrm{mmol})$ in pyridine $(28 \mathrm{ml})$ was added dropwise, with stirring. The temperature was then allowed to rise to room temperature during
$6 \mathrm{~h}$ (6). The reaction mixture was diluted with dichloromethane, washed with water, dried over sodium sulfate, and concentrated. Crystallization from ethanol yielded pure $1(6.9 \mathrm{~g}, 78 \%), \mathrm{mp} 132-133^{\circ} \mathrm{C}$, $[\alpha]_{\mathrm{D}}+140^{\circ}\left(c 1, \mathrm{CHCl}_{3}\right)$. Found: $\mathrm{C} 63.3 ; \mathrm{H} 4.87 ; \mathrm{N} 2.71$. $\mathrm{C}_{26} \mathrm{H}_{23} \mathrm{NO}_{9}$ requires: $\mathrm{C} 63.3 ; \mathrm{H} 4.70 ; \mathrm{N} 2.84$.

p-Nitrophenyl 3-O-benzoyl-4,6-O-benzylidene-2-O$(2,3,4,6$-tetra- $O$-acetyl- $\alpha-D$-galactopyranosyl $)-\alpha-D$ mannopyranoside (2). A mixture of $1(1.0 \mathrm{~g}, 2 \mathrm{mmol})$, 2,3,4,6-tetra- $O$-acetyl- $\alpha$-D-galactopyranosyl bromide $(2.5 \mathrm{~g}, 6 \mathrm{mmol})$, and mercuric cyanide $(1.6 \mathrm{~g}, 6.3 \mathrm{mmol})$ was dissolved in dry acetonitrile $(10 \mathrm{ml})$ and stirred at room temperature for $48 \mathrm{~h}$. The reaction mixture was diluted with dichloromethane and washed with saturated aqueous sodium hydrogen carbonate, water, and finally concentrated to a syrup. Column chromatography on silica gel with toluene-ethyl acetate (4:1) yielded chromatographically homogeneous 2 $(610 \mathrm{mg}, 37 \%)$. The material crystallized from ethanol, mp $112-114^{\circ} \mathrm{C},[\alpha]_{\mathrm{D}}+115^{\circ}\left(c 3, \mathrm{CHCl}_{3}\right)$. Found: $\mathrm{C} 58.2$; $\mathrm{H}$ 5.08; $\mathrm{N} 1.68 . \mathrm{C}_{40} \mathrm{H}_{41} \mathrm{NO}_{18}$ requires: $\mathrm{C} 58.3 ; \mathrm{H} \mathrm{5.02}$; N 1.70 .

Gal-(1" 2$)-M a n-(1 \stackrel{2 "}{\rightarrow})-P N P$. A solution of $2(250$ $\mathrm{mg}, 0.3 \mathrm{mmol})$ in aqueous acetic acid $(15 \mathrm{ml}, 80 \%)$ was kept at $95-100^{\circ} \mathrm{C}$ for $15 \mathrm{~min}$. The solution was concentrated and evaporated twice with toluene ( 20 $\mathrm{ml})$ to remove acetic acid. The resulting residue was catalytically deacylated with methanol containing sodium methoxide and purified by chromatography

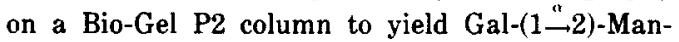
$(1 \stackrel{\circ}{\rightarrow})$-PNP $(120 \mathrm{mg}, 80 \%)$ as a chromatographically homogeneous syrup, $[\alpha]_{\mathrm{D}}+129^{\circ}\left(c 1, \mathrm{H}_{2} \mathrm{O}\right)$.

An aliquot of the product was hydrolyzed with 0.25 $M$ aqueous sulfuric acid at $100^{\circ} \mathrm{C}$ for $16 \mathrm{~h}$. The resulting material was reduced with sodium borohydride and acetylated (7), to yield two hexaacetates in a ratio of 1:1 which were indistinguishable from galactitol hexaacetate and mannitol hexaacetate standards on gle.

Another aliquot of Gal-( $1 \stackrel{\text { "r }}{\rightarrow} 2)-\operatorname{Man}-(1 \stackrel{\circ}{\rightarrow} 0)$-PNP was methylated (8), hydrolyzed, reduced with sodium borohydride, and acetylated (9). The two $O$-methylalditol acetates thus obtained were indistinguishable from 1,5-di- $O$-acetyl-2,3,4,6-tetra- $O$-methyl-Dgalactitol and 1,2,5-tri- $O$-acetyl-3,4,6-tri- $O$-methyl$\mathrm{D}-\mathrm{mannitol}$, respectively, on glc and $\mathrm{ms}$.

p-Nitrophenyl 3-O-benzoyl-4,6-O-benzylidene-2-O$(2,3,4,6$ - tetra - $O$ - acetyl $-\alpha-D-$ glucopyranosy $l)-\alpha-D$ mannopyranoside (3). A mixture of $1(1.0 \mathrm{~g}, 2 \mathrm{mmol})$, 2,3,4,6-tetra- $O$-acetyl- $\alpha$-D-glucopyranosyl bromide (2.5 $\mathrm{g}, 6 \mathrm{mmol})$, and $1.6 \mathrm{~g},(6.3 \mathrm{mmol})$ mercuric cyanide in $d r y$ acetonitrile $(10 \mathrm{ml})$ was reacted and the product worked up and separated as described for the preparation of 2 to afford $3(310 \mathrm{mg}, 18 \%)$ which crystallized from ethanol, $m p 107-110^{\circ} \mathrm{C},[\alpha]_{\mathrm{D}}+110^{\circ}$ (c $1, \mathrm{CHCl}_{3}$ ). Found: C 58.2; $\mathrm{H} .00 ; \mathrm{N} 1.85 . \mathrm{C}_{40} \mathrm{H}_{41} \mathrm{NO}_{18}$ requires: $\mathrm{C} 58.3 ; \mathrm{H} 5.02 ; \mathrm{N} 1.70$.

Glc- $(1 \stackrel{*}{\rightarrow} 2)-\operatorname{Man}-(1 \stackrel{*}{\rightarrow} O)-P N P$. Deprotection was 
carried out as described above for the preparation

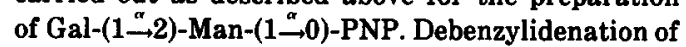
(3) $(130 \mathrm{mg}, 0.16 \mathrm{mmol}$ ) followed by chromatography on silica gel with chloroform-acetone (3:1) as eluant afforded $p$-nitrophenyl 3-O-benzoyl-2-O-(2,3,4,6-tetra0 -acetyl $\alpha$-D-glucopyranosyl)- $\alpha$-D-mannopyranoside (100 mg, 86\%), $[\alpha]_{\mathrm{D}}+108^{\circ}\left(\mathrm{c} 2, \mathrm{CHCl}_{3}\right)$. Deacylation (of $160 \mathrm{mg}$ ) and purification on Bio-Gel P2 afforded Glc-( $\left.1^{\circ} 2\right)-M a n-(1 \stackrel{\alpha}{\rightarrow} O)$-PNP $(90 \mathrm{mg}, 89 \%),[\alpha]_{\mathrm{D}}$ $+135^{\circ}$ (c 2, $\mathrm{H}_{2} \mathrm{O}$ ).

Sugar and methylation analysis as described above for Gal-(1 $\stackrel{\alpha}{\rightarrow} 2)-M a n-(1 \stackrel{\alpha}{\rightarrow} 0)-P N P$ yielded, respectively, glucitol and mannitol hexaacetates in a $1: 1$ ratio and 1,5-di- $O$-acetyl-2,3,4,6-O-methyl-D-glucitol and 1,2,5-tri- $O$-acetyl-3,4,6-tri- $O$-methyl-D-mannitol as judged from their behavior on gle and $\mathrm{ms}$ which was indistinguishable from authentic materials.

$p$-Nitrophenyl $\alpha$-maltoside was purchased from Calbiochem-Behring Corporation, La Jolla, California.

\section{RESULTS AND DISCUSSION}

The binding modes depicted in Figs. 1A and $B$ and the reaction scheme of Eq. [1] predict that only glycosides containing two or more $\alpha-(1 \rightarrow 2)$-linked glycosyl residues that are capable of interaction with the primary glycosyl binding site on con A should yield a multiphasic time dependence of binding. ${ }^{4}$ In order to test this hypothesis, we have determined kinetics for binding of $\alpha$-D-Gle $p-(1 \rightarrow 2)-\alpha-\mathrm{D}-\mathrm{Man} p-(1 \rightarrow$ $O)-\mathrm{PNP}$ and $\alpha-\mathrm{D}-\mathrm{Gal} p-(1 \rightarrow 2)-\alpha-\mathrm{D}-\mathrm{Man} p-$ $(1 \rightarrow 0)-P N P$ to con $A$. The time-dependent changes in absorbance illustrated in Fig. 2 show that the binding of $\alpha$-D-Glc $p-(1 \rightarrow 2)-$ $\alpha$-D-Man $p-(1 \rightarrow 0)$-PNP to con $\mathrm{A}$ is a biphasic process as one might expect from the orientations of the ligand in the con $A$ binding site shown in Figs. $1 A$ and $B$, inasmuch as both the glucopyranosyl and mannopyranosyl residues can interact with the primary glycosyl binding site of con A (Figs. 3A and B) (10). In contrast to this

\footnotetext{
${ }^{4}$ Substitution at oxygen atoms other than $O-1$ and $0-2$ of a glycosyl residue results in a loss of the ability of the glycosyl residue to occupy the primary glycosyl binding site of con $A$. The interactions between glycosyl groups and the primary glycosyl binding site of con A depicted in Figs. 1, 3, and 5 are based on the results of several studies of the specificity of con A. See Ref. (10) for a discussion of some of this work.
}

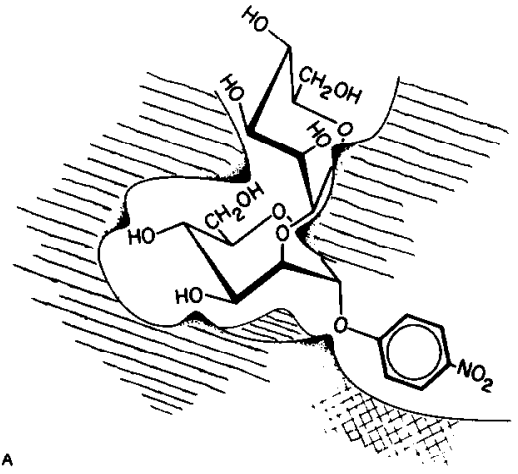

A

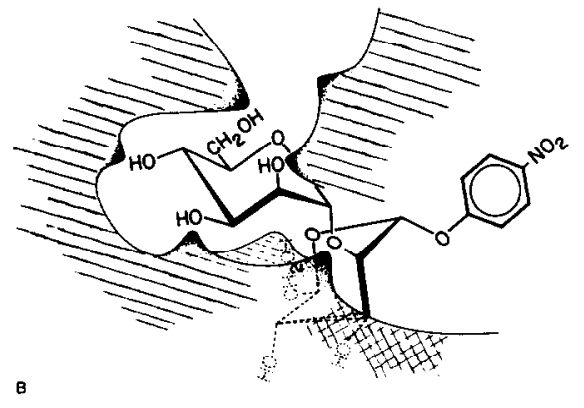

FIg. 1. Pictorial representation of the PL and PL* complexes for binding of $\operatorname{Man}-(1 \stackrel{\alpha}{\rightarrow} 2)-\operatorname{Man}-(1 \stackrel{\alpha}{\rightarrow} 0)$ PNP to con A. (A) PL binding mode; (B) PL* binding mode.

biphasic binding process, the time dependence of binding of $\alpha-\mathrm{D}-\mathrm{Gal} p-(1 \rightarrow 2)-\alpha-\mathrm{D}-$ $\operatorname{Man} p-(1 \rightarrow 0)-P N P$ is in agreement with a monophasic process (Fig. 4). This result is consistent with our hypothesis for the interaction of disaccharides with con $A$ as put forth in Figs. 1A and B and in Eq. [1]. Galactopyranosyl residues do not interact with the primary carbohydrate binding site of con A (11). Therefore, the pathway depicted in Eq. [1] requires that $\alpha-\mathrm{D}-\mathrm{Gal} p$ $(1 \rightarrow 2)-\alpha-D-M a n p-(1 \rightarrow O)-P N P$ binds to con A solely in the $\mathrm{PL}$ mode (Fig. 5) with monophasic kinetics in a manner analogous to $\alpha$-D-Man $p-(1 \rightarrow O)-P N P$.

Our results indicate that if binding of disaccharides occurs via Eq. [2], the PL to PL* transition would represent a reorientation of oligosaccharide ligand wherein an interchange of the glycosyl residue occupying the primary glycosyl binding site occurs without dissociation of the ligand. Although such a pathway cannot be ruled 


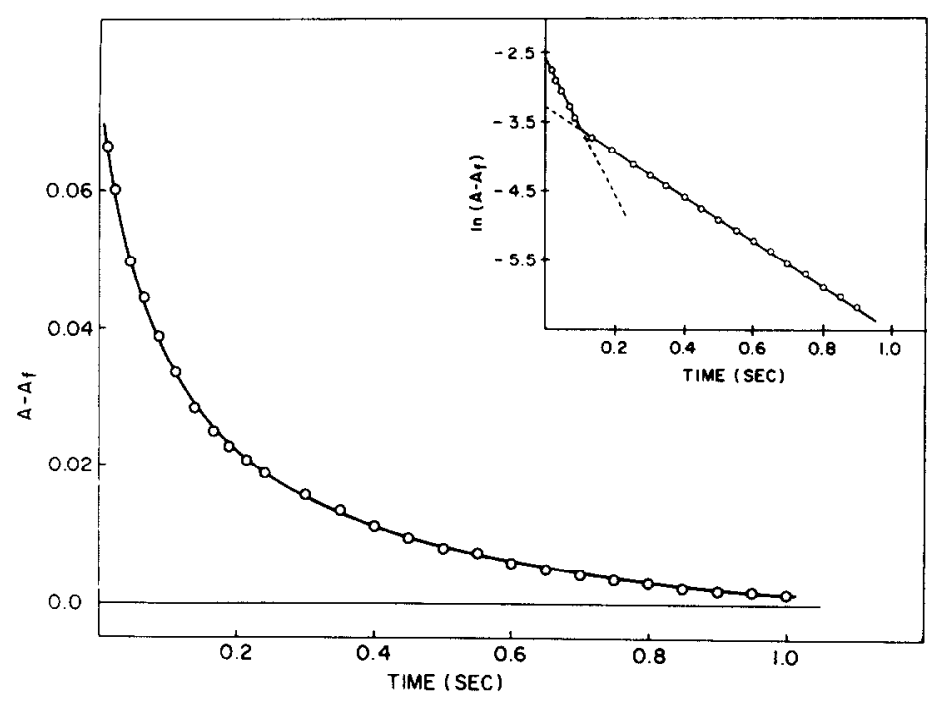

FIG. 2. Time dependence of absorbance $(317 \mathrm{~nm})$ for reaction of con $A(359 \mu \mathrm{M})$ with Glc$(1 \stackrel{a}{\rightarrow} 2)-\mathrm{Man}-(1 \stackrel{\alpha}{\rightarrow} O)-P N P(42 \mu \mathrm{M})$. The semi-log plot in the inset illustrates the biphasic nature of the reaction.

out, analysis of the binding of $\alpha-\mathrm{D}-\mathrm{Man} p-$ $(1 \rightarrow 2)-\alpha-D-M a n p-(1 \rightarrow O)$-PNP in terms of the pathway depicted in Eq. [2] results in
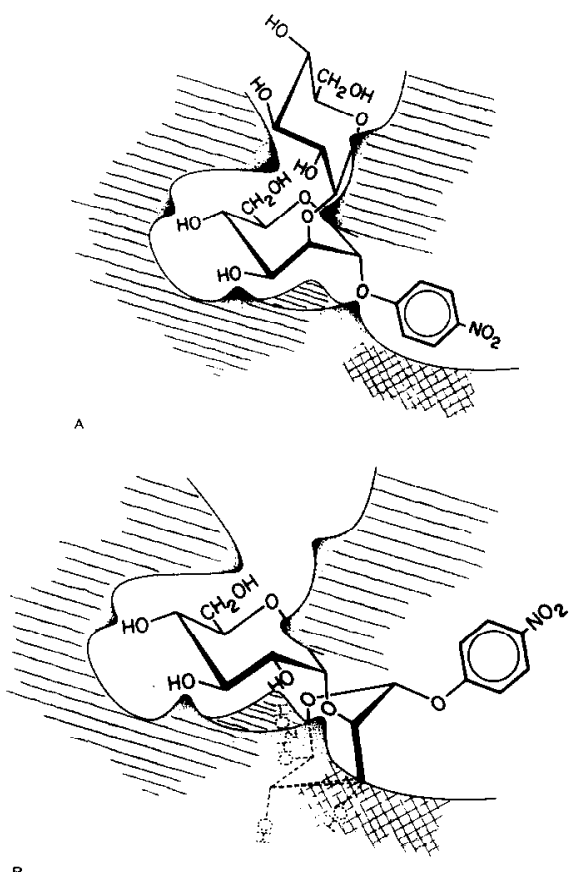

FIG. 3. Pictorial representation of the PL and PL*

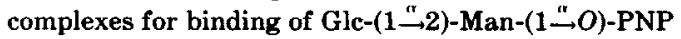
to con A. (A) PL binding mode; (B) $P L^{*}$ binding mode. unusual spectral properties for PL and PL* (1). According to the pathway of Eq. [2] (but not that of Eq. [1]), PL and PL* would have identically shaped spectra and identical wavelengths of maximal absorbance, but PL and PL* would have molar absorptivities which differ by the same constant factor at each wavelength. Such a difference in the spectral properties of the chromogenic reporter group is not characteristic of a simple change in environment of the chromogenic group. Changes in environment of the chromogenic group usually result in spectral shifts in position of maximal absorbance, or in changes in the spectral bandwidth which result in changes in the shape of the spectrum of the chromogenic group.

Thus, we have chosen to analyze our kinetic data in terms of the pathway depicted in Eq. [1], which provides the simplest explanation of our observations. Values for rate and equilibrium constants obtained by analyzing the time dependence of absorbance according to the reaction scheme in Eq. [1] are listed in Table I. Analysis of the time dependence of absorbance at several wavelengths indicates that the spectrum of the $p$-nitrophenyl group in $\alpha$-D-Glc $p-(1 \rightarrow 2)-\alpha-\mathrm{D}-\mathrm{Man} p$ - 


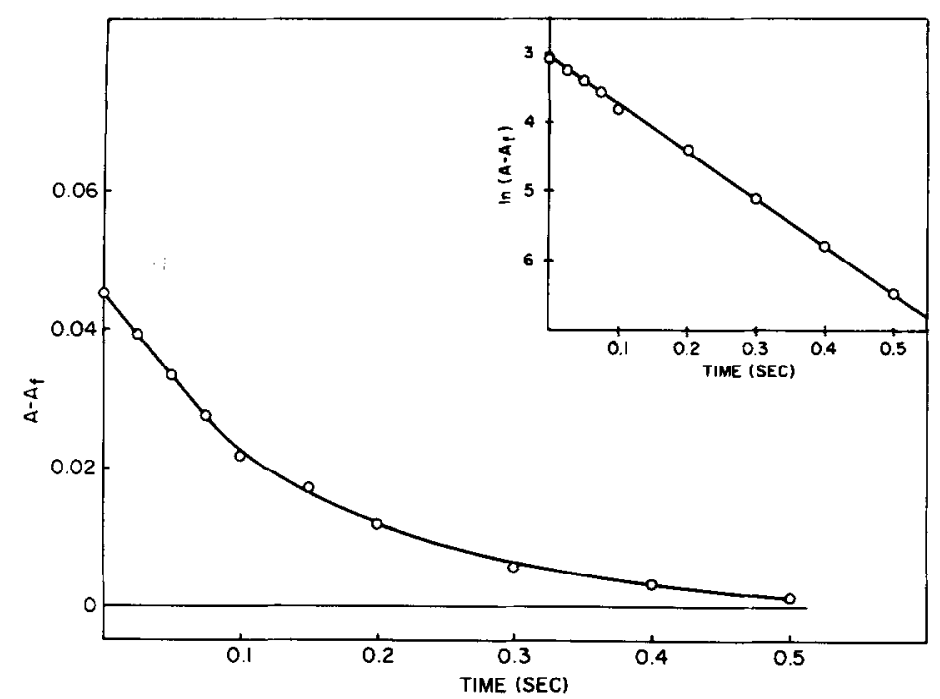

FIG. 4. Time dependence of absorbance $(317 \mathrm{~nm})$ obtained for reaction of con A (217 $\mu \mathrm{M})$ with Gal-(1 $\stackrel{\sim}{\rightarrow})$ )-Man- $(1 \stackrel{*}{\rightarrow} O)$-PNP $(20 \mu \mathrm{M})$. The semi-log plot in the inset illustrates the monophasic nature of the reaction.

$(1 \rightarrow 0)$-PNP is blue shifted in PL and is essentially unaltered in PL*. These observations, which are similar to those previously made with $\alpha$-D-Man $p-(1 \rightarrow 2)-\alpha-\mathrm{D}-$ $\operatorname{Man} p-(1 \rightarrow O)-P N P$, indicate that the nitrophenyl group occupies an apolar environment in PL (Fig. 1A) and an aqueouslike environment in $\mathrm{PL}^{*}$ (Fig. 1B).

The orientations of the nitrophenyl group in PL and PL* as depicted in Figs. $1 A$ and $B$, respectively, indicate that the polarity in the environment of the nitrophenyl reporter group of a bound glycoside is a function of its disposition relative to

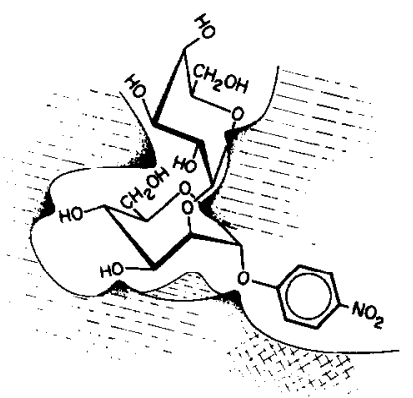

FIG. 5. Pictorial representation of the PL complex for binding of $\operatorname{Gal}-(1 \stackrel{\alpha}{\rightarrow} 2)-\mathrm{Man}-(1 \stackrel{\alpha}{\rightarrow} 0)$-PNP to $\operatorname{con} \mathrm{A}$. the primary glycosyl binding site. In order to further characterize the environment in the vicinity of the glycosyl binding site, the interaction of con A with $\alpha$-D-Glcp$(1 \rightarrow 4)-\alpha-D-G l c p-(1 \rightarrow O)-P N P$ was investigated. Only the glycosyl residue at the nonreducing terminus of this $\alpha$-(1-4)-linked disaccharide can interact with the primary binding site of con A (Fig. 6). ${ }^{4}$ Thus, the nitrophenyl reporter group in this disaccharide cannot occupy the same site that accepts the nitrophenyl group in PL and in con A complexes of nitrophenyl glycosides of monosaccharides. As shown in Fig. 7, no difference spectrum is generated upon mixing con A with $\alpha$-D-Glcp$(1 \rightarrow 4)-\alpha-\mathrm{D}-\mathrm{Glc} p-(1 \rightarrow O)-\mathrm{PNP}$. This result contrasts with that of the difference spectrum obtained upon mixing con $A$ with nitrophenyl glycosides such as $\alpha$-D-Man $p$ $(1 \rightarrow O)$-PNP and $\alpha$-D-Glep-(1つO)-PNP

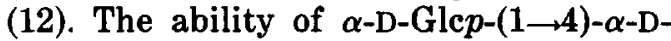
Gle $p-(1 \longrightarrow O)$-PNP to reduce the magnitude of the difference spectrum seen upon mix-

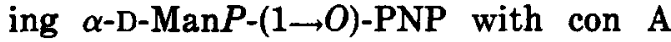
(Fig. 7) indicates that the disaccharide does indeed bind to con $\mathrm{A}$ as expected. Interestingly, the nitrophenyl group in bound $\alpha-\mathrm{D}-\mathrm{Gle} p-(1 \rightarrow 4)-\alpha-\mathrm{D}-\mathrm{Gle} p-(1 \rightarrow O)-\mathrm{PNP}$ appears to be situated entirely in an aqueous- 


\section{TABLE I}

KINETIC AND EQULIBRIUM CONSTANTS FOR THE BINDING OF LIGANDS TO con A

\begin{tabular}{|c|c|c|c|c|c|c|}
\hline & $\begin{array}{c}10^{-4} k_{23} \\
\left(\sec ^{-1} \mathrm{M}^{-1}\right)\end{array}$ & $\begin{array}{c}k_{32} \\
\left(\sec ^{-1}\right)\end{array}$ & $\begin{array}{c}10^{-4} K_{\mathrm{PL}}{ }^{a} \\
\left(\mathrm{M}^{-1}\right)\end{array}$ & $\begin{array}{c}10^{-4} k_{21} \\
\left(\sec ^{-1} M^{-1}\right)\end{array}$ & $\begin{array}{c}k_{12} \\
\left(\sec ^{-1}\right)\end{array}$ & $\begin{array}{c}10^{-4} K_{\mathrm{PL}}:^{b} \\
\quad\left(\mathrm{M}^{-1}\right)\end{array}$ \\
\hline 2-O-Me-Man $(1 \stackrel{*}{\rightarrow} O)-\mathrm{PNP}^{c}$ & 6.6 & 8.2 & 0.8 & & & \\
\hline Gal-(1 $\underset{a}{\stackrel{\prime \prime}{\rightarrow}} 2)-\operatorname{Man}-(1 \stackrel{*}{\rightarrow} 0)-P N P$ & 2.4 & 1.3 & $1.8(2.1)^{e}$ & & & \\
\hline Glc- $(1 \stackrel{\alpha}{\rightarrow} 2)-\operatorname{Man}-(1 \stackrel{*}{\rightarrow} O)-\mathrm{PNP}^{d}$ & 3.0 & 1.1 & 2.7 & 2.9 & 7.9 & 0.37 \\
\hline $\operatorname{Man}-(1 \stackrel{*}{\rightarrow} 2)-\operatorname{Man}-(1 \stackrel{*}{\rightarrow} O)-\mathrm{PNP}^{c}$ & 3.2 & 0.22 & 14.5 & 2.3 & 1.1 & 2.1 \\
\hline
\end{tabular}

${ }^{a}$ Determined using the relationship $K_{\mathrm{PL}}=k_{23} / k_{32}$.

${ }^{b}$ Determined using the relationship $K_{\mathrm{PL}}=k_{21} / k_{12}$.

${ }^{c}$ Constants obtained from Ref. (1).

${ }^{d}$ Rate constants and errors were derived from the dependence of the fast and slow phases on [P], the off rate constant, and measured equilibrium constants as discussed in the experimental section. Standard deviations for the rate constants were less than $10 \%$.

"Determined from an independent spectrophotometric titration.

like environment as suggested by the absence of a difference in the spectrum of the reporter group in the free and bound ligand. This result is consistent with the model which predicts that the nitrophenyl group in $\alpha$-D-Glc $p-(1 \rightarrow 4)-\alpha$-D-Gle $p-(1 \rightarrow O)$ PNP is unable to occupy the same hydrophobic site on con A which accepts the nitrophenyl group in PL complexes.

The proposed binding orientations of the ligand in the con A binding site further predicts that complex oligosaccharides having more than one glycosyl residue which can interact with the primary glycosyl binding site of con A, might exhibit multiphasic binding kinetics wherein the maximum number of observable phases would correspond to the number of glycosyl residues. This expectation is borne out by the recent observation of the triphasic time dependence reported for 4-



FIG. 6. Pictorial representation of the $\mathrm{PL}^{*}$ complex for binding of $p$-nitrophenyl $\alpha$-maltoside (Glc$(1 \stackrel{\circ}{\rightarrow} 4)-$ Glc- $(1 \stackrel{\circ}{\rightarrow} 0)-$ PNP) to con A. methylumbelliferyl-labeled trisaccharide, $\alpha$-D-Man $p-(1 \rightarrow 2)-\alpha$-D-Man $p-(1 \rightarrow 2)-\alpha-\mathrm{D}-$ $\operatorname{Man} p-(1 \rightarrow O)-\mathrm{MeUmb}(2)$.

The equilibrium constants for PL complexes listed in Table I provide informa-

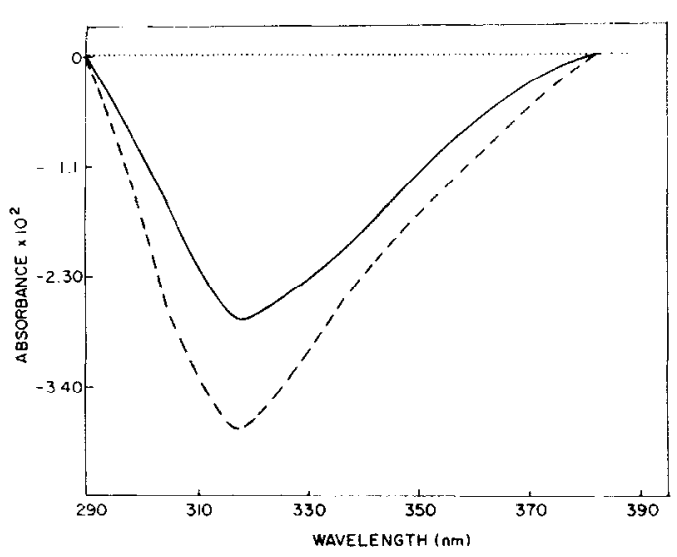

FIG. 7. Competition of Glc- $(1 \stackrel{\alpha}{\rightarrow} 4)$-Glc- $(1 \stackrel{\alpha}{\rightarrow} 0)-$ PNP and Man- $(1 \stackrel{\alpha}{\rightarrow} O)$-PNP for con $A$. The plotted difference spectra are differences between spectra of mixed and unmixed components corrected fur concentration differences. The spectra were taken in $0.88-\mathrm{cm}$ pathlength split compartment cells. The concentrations (after mixing) of con $A$ and each specified ligand were $40 \mu \mathrm{M}$ and $100 \mu \mathrm{M}$, respectively. $(\ldots \ldots)$ Con $A$ and Glc- $(1 \stackrel{\alpha}{\rightarrow} 4)-$ Glc- $(1 \stackrel{\alpha}{\rightarrow} 0)$-PNP. This difference spectra could not be increased by increasing the con A concentration to $800 \mu \mathrm{M}$ and the ligand concentration to $200 \mu \mathrm{M}$. $(---)$ Con $A$ and $\operatorname{Man}-(1 \stackrel{\alpha}{\rightarrow} 0)$ PNP; $(-)$ con A, Man- $(1 \stackrel{a}{\rightarrow} 0)-P N P$, and Gle$(1 \stackrel{\alpha}{\rightarrow} 4)-G l c-(1 \stackrel{\alpha}{\rightarrow} 0)-$ PNP. 
tion about the specificity of interactions between con $A$ and complex carbohydrates with more than one glycosyl residue. The affinity of con $A$ for $p$-nitrophenyl 2-Omethyl- $\alpha$-D-mannopyranoside, the reference monosaccharide listed in Table $\mathrm{I}$, is essentially the same as that for $p$-nitrophenyl $\alpha$-D-mannopyranoside, which is unsubstituted at $0-2$ (1). Introduction of an $\alpha$-D-galactopyranosyl residue at the $O$ 2 position of the mannopyranosyl results in a 2.2-fold increase in the affinity of the ligand for con $A$. With a glucopyranosyl residue at the same $0-2$ position, the equilibrium constant for formation of $\mathrm{PL}$ is 3.4-fold larger than for formation of a complex with the 2-0-methyl mannopyranosyl derivative. Substitution of a mannopyranosyl group at $0-2$, however, leads to an 18-fold increase in the equilibrium constant for formation of PL. These results indicate that at least one hydroxyl group on the nonreducing end of the disaccharides can interact with the protein in the extended site, and that an axial orientation of the hydroxyl group at C-2 of the nonreducing glycopyranosyl group is probably the most important determinant for enhancing binding to con $\mathrm{A}$. The two binding modes $\mathrm{PL}$ and $\mathrm{PL}^{*}$ depicted in Figs. $1 A$ and $B$ indicate that in the $\mathrm{PL}^{*}$ complex the glycosyl residue at the nonreducing terminus of the disaccharide occupies the main glycosyl binding site on con $A$, whereas in the PL complex, the glycosyl residue at the reducing end of the disaccharide occupies the principal glycosyl binding site. The lowered equilibrium constant for formation of the $\mathrm{PL}^{*}$ complex with $\alpha$-D-Man $p-(1 \rightarrow 2)-\alpha-D-M a n p-$ $(1 \rightarrow 0)$-PNP in comparison to that for formation of the PL complex is consistent with the view that in the $\mathrm{PL}^{*}$ complex, extended interactions are much less important with this disaccharide.

Recent work (14) has attributed the increased affinity of certain $\alpha-(1 \rightarrow 2)$-linked disaccharides toward con $A$ to a purely statistical enhancement of binding rather than being due to contributions from simultaneous interactions with groups on both glycosyl moieties. This view fails to account for our observations. If the enhanced affinity of con $\mathrm{A}$ for certain disaccharides were only statistical in nature, one would expect $\alpha$-D-Man $p-(1 \rightarrow 2)-\alpha-D-$ Man $p-(1 \rightarrow 0)$-PNP with two mannopyranosyl residues to bind to con $A$ at twice the rate and with twice the affinity as the monosaccharide $p$-nitrophenyl 2-O-methyl$\alpha$-D-mannopyranoside. Instead, the disaccharide forms the PL complex at half the rate and with 18 times the affinity of the monosaccharide. Another indication that the statistical argument is incorrect and that con $A$ is capable of interactions with groups in both glycosyl residues of certain disaccharides is indicated by the different activation enthalpies listed in Table II for the formation and dissociation of complexes of con A and disaccharides. If the differences in the way disaccharides bind to con A were due entirely to statistical effects, differences in the activation parameters for the binding of $\alpha$-D-Man$p-(1 \rightarrow 2)-\alpha-\mathrm{D}-\mathrm{Man} p-(1 \rightarrow 0)-\mathrm{PNP}$ and $\alpha$-DGal $p-(1 \rightarrow 2)-\alpha-\mathrm{D}-\mathrm{Man} p-(1 \rightarrow 0)$-PNP should be confined to the entropies of activation since these disaccharides differ only in the number of glycosyl residues capable of interacting with the primary glycosyl binding site of con A. Instead, substantial differences in both enthalpies and entropies of activation which cannot be attributed to statistical effects are observed for formation and dissociation of complexes between con $A$ and these disaccharides.

It should be noted that the observations presented here indicating the existence of extended interactions between con $A$ and oligosaccharides don't require the presence of individual subsites for each glycosyl residue as exist in wheat germ agglutinin (16). Our results do indicate, however, that con A can interact simultaneously with groups on both glycosyl residues of certain disaccharides. The structural determinants for the specific interactions between con A and a glycosyl residue bound to the primary glycosyl binding site have been established by previous studies. ${ }^{4}$ Results presented in this work indicate the existence of at least one extended interaction between con $A$ and 
TABLE II

ACtivation Parameters for Formation (a) AND BREakdown (-a) OF COMPLEXES OF con $\mathrm{A}^{\prime \prime}$

\begin{tabular}{|c|c|c|c|c|}
\hline & $\begin{array}{c}\Delta H_{\mathrm{a} \ddagger} \\
\text { (kcal/mol) }\end{array}$ & $\begin{array}{c}\Delta H_{-\mathrm{a}} \ddagger \\
(\mathrm{kcal} / \mathrm{mol})\end{array}$ & $\begin{array}{l}\Delta S_{\mathrm{a}_{u}} \ddagger \\
(\mathrm{eu})\end{array}$ & $\begin{array}{l}\Delta S_{-a_{u}} \ddagger \\
\text { (eu) }\end{array}$ \\
\hline Gle- $(1 \stackrel{\sim}{\rightarrow} 2)-\operatorname{Man}-(1 \stackrel{\sim}{\rightarrow} 0)-$ PNP & $13.8 \pm 0.7$ & $13.0 \pm 0.3$ & $17.3 \pm 2.4$ & $-15.0 \pm 1.0$ \\
\hline $\operatorname{Man}-(1 \stackrel{*}{\rightarrow} 2)-\operatorname{Man}-(1 \stackrel{*}{\rightarrow} 0)-\mathrm{PNP}^{b}$ & $13.8 \pm 0.3$ & $9.4 \pm 0.1$ & $16.6 \pm 1.1$ & $3.3 \pm 0.3$ \\
\hline Gal-(1 $\stackrel{\star r}{\rightarrow} 2)-M a n-(1 \stackrel{r}{\rightarrow} 0)$-PNP & $9.6 \pm 0.08$ & $16.0 \pm 0.03$ & $4.7 \pm 0.1$ & $-5.0 \pm 0.1$ \\
\hline $\operatorname{Man}-(1 \stackrel{a}{\rightarrow} 0)-\mathrm{PNP}^{c}$ & $9.5 \pm 0.3$ & $16.8 \pm 0.2$ & $2.8 \pm 1.1$ & $1.3 \pm 0.7$ \\
\hline
\end{tabular}

${ }^{a}$ Activation parameters were determined as described in Ref. (4) (for disaccharides which form two complexes, the parameters are for formation and breakdown of PL). The entropies of activation are unitary values and do not contain the entropy lost upon bringing two molecules together in a $1 \mathrm{M}$ solution. They were obtained using the relationship of Ref. (15), $\Delta S_{\mathrm{u}} \ddagger=\Delta S \ddagger+7.98$, where $\Delta S \ddagger$ is the observed entropy of activation when concentrations of reactants are expressed in molar units.

${ }^{b}$ Activation parameters were obtained from data of Ref. (1).

${ }^{c}$ Activation parameters were obtained from Ref. (4).

an axial hydroxyl group at C-2 of the nonreducing glycosyl group of certain disaccharides. This interaction accounts for the 5 - to 18-fold greater affinity of con A for $\alpha$-D-Man $p$ - $(1 \rightarrow 2)$ - $\alpha$-D-Man $p-(1 \rightarrow 0)$-PNP over the monosaccharide and disaccharides listed in Table I, which are not capable of the extended interaction. In a study similar to our study (1) of the binding of $\alpha$-D-Manp-(1 $\rightarrow O)$-PNP and $\alpha$-DMan $p-(1 \rightarrow 2)-\alpha$-D-Man $p-(1 \rightarrow O)$-PNP to con A, Van Landschoot et al. (2) determined the kinetics of binding of $\alpha$-D-Man $p-(1 \rightarrow O)$ MeUmb, $\alpha$-D-Man $p$-(1 $\rightarrow 2)-\alpha$-D-Man $p$ $(1 \rightarrow 0)-M e U m b$, and $\alpha$-D-Man $p-(1 \rightarrow 2)-\alpha$-D$\operatorname{Man} p-(1 \rightarrow 2)-\alpha$-D-Man $p-(1 \rightarrow 0)-M e U m b$, to con $A$ using the change in fluorescence and absorbance of the 4-methylumbelliferyl reporter group to monitor binding. In contrast to our observations with the nitrophenyl glycosides, Van Landschoot et al. only observed a 3.3-fold greater affinity of con $\mathrm{A}$ for the methylumbelliferyl disaccharide relative to the monosaccharide. Furthermore, it was observed that con A bound the methylumbelliferyl trisaccharide less tightly than the disaccharide, and only 1.9 times more tightly than the monosaccharide. Van Landschoot et al. also observed that the environment of the fluorescent methylumbelliferyl reporter group in each of the two binding modes for the con A-bound disaccharide was dif- ferent than the environment of the methylumbelliferyl group in the con A-bound monosaccharide. These conclusions which are based on the different spectral properties determined for the bound reporter group suggest that in both binding modes observed for $\alpha$-D-Man $p$-(1 $\rightarrow 2)-\alpha$-D-Man $p$ $(1 \rightarrow 0)-M e U m b$, the interactions between con $A$ and this disaccharide may be substantially different than those observed for $\alpha$-D-Manp- $(1 \rightarrow 0)$-MeUmb. Since it appears that these mono- and disaccharides may well bind to con $A$ in different orientations, it is difficult to reach any conclusions regarding the existence or nonexistence of extended interactions from a single comparison of the affinity of con A for the mono- and disaccharide.

It should be noted, however, that although con A only shows a modest 3.3-fold increase in its affinity for the methylumbelliferyl-labeled disaccharide over the monosaccharide, essentially none of this modest increase in affinity can be ascribed to a statistical effect arising from the presence of two mannopyranosyl units and two binding modes for the disaccharide. The maximum statistical enhancement of 2 for the binding of the disaccharide relative to the monosaccharide would be achieved only if both binding modes were equally stable. However, one binding mode was observed to be favored by 68 -fold over 
the other binding mode. With one binding mode 68-fold more stable than the other, the maximum statistical enhancement for binding the disaccharide would be 1.015 (i.e., $1+1 / 68$ ).

Our observations of similar spectral properties for the bound nitrophenyl group in the monosaccharide and in one of the binding modes of the disaccharide suggests similar orientations for the con Abound ligand. Thus, it appears reasonable to compare the free energy for binding the nitrophenyl monosaccharide with that for binding the nitrophenyl disaccharide in the corresponding binding mode.

The reason for the apparent difference in ligand binding seen with the methylumbelliferyl and nitrophenyl glycosides is not clear at this time. The apparent perturbations in binding observed with the methylumbelliferyl derivatives might well arise, however, from interactions between the con $A$ and the methylumbelliferyl reporter group which don't exist with the nitrophenyl group. This contention is supported by the observation that con $\mathrm{A}$ binds


better than that $\alpha-\mathrm{D}-\mathrm{Man} p-(1 \rightarrow O)-\mathrm{Me}$, whereas con $A$ binds $\alpha$-D-Man $p-(1 \rightarrow O)$ PNP less than twofold better than $\alpha$-D$\operatorname{Man} p-(1 \longrightarrow O)$-Me.

\section{ACKNOWLEDGMENTS}

We are indebted to Professor Bengt Lindberg for his interest and to Miss Jean Ahlborg and Mr. Paul Ducharme of the Naval Medical Research Institute for their help in obtaining equilibrium and kinetic measurements.

\section{REFERENCES}

1. Williams, T. J., Shafer, J. A., Goldstein, I. J., AND Adamson, T. (1978) J. Biol. Chem. 253, 8538-8544.

2. Van Landschoot, A., LoOntiens, F. G., ClegG, R. M., AND Jovin, T. M. (1980) Eur. J. Biochem. 103, 313-321.

3. Williams, T. J., Shafer, J. A., and Goldstein, I. J. (1978) J. Biol. Chem. 253, 8533-8537.

4. Lewis, D. S., Shafer, J. A., AND Goldstein, I. J. (1976) Arch. Biochem. Biophys. 172, 689695.

5. Ekborg, G., GaregG, P. J., AND GotThammaR, B. (1975) Acta Chem. Scand. B29, 765-771.

6. Seymour, F. R. (1974) Carbohyd. Res. 34, 65-70.

7. SAWARDEKER, J. S., SLONEKER, J. H., AND JEANES, A. (1965) Anal. Chem. 37, 1602-1604.

8. HA Komori, S. (1964) J. Biochem. (Tokyo) 55, 205208.

9. BJORNDAL, H., HellerQuiST, C. G., LINDBERG, B., AND Svensson, S. (1970) Angew. Chem. Int. Ed. Engl. 9, 610-619.

10. Goldstein, I. J., REICHeRT, C. M., AND Misaki, A. (1974) Ann. N.Y. Acad. Sci. 234, 283-296.

11. Goldstein, I. J., Hollerman, C. E., aNd SMith, E. E. (1965) Biochemistry 4, 876-883.

12. Hassing, G. S., AND GoldSTEIN, I. J. (1970) Eur. J. Biol. Chem. 16, 549-556.

13. Bessler, W., Shafer, J. A., AND Goldstein, I. J. (1974) J. Biol. Chem. 249, 2819-2822.

14. Brewer, C. F., AND Brown, R. D. (1979) Biochemistry 18, 2555-2562.

15. KaUzmanN, W. (1959) in Advances in Protein Chemistry (Anfinsen, C. B., Jr., Anson, M. L., Bailey, K., and Edsall, J. T. eds.), Vol. 14, pp. 33-35, Academic Press, New York.

16. Allen, A. K., NeUberger, N., aND Sharon, N. (1973) Biochem. J. 131, 155-162. 